\title{
BMJ Open A comparison study on the prevalence of obesity and its associated factors among city, township and rural area adults in China
}

\author{
Yan Zou, ${ }^{1}$ Ronghua Zhang, ${ }^{1}$ Biao Zhou, ${ }^{1}$ Lichun Huang, ${ }^{1}$ Jiang Chen, ${ }^{1}$ Fang Gu, ${ }^{1}$ \\ Hexiang Zhang, ${ }^{1}$ Yueqiang Fang, ${ }^{1}$ Gangqiang Ding $^{2}$
}

To cite: Zou Y, Zhang R, Zhou B, et al. A comparison study on the prevalence of obesity and its associated factors among city, township and rural area adults in China. BMJ Open 2015;5: e008417. doi:10.1136/ bmjopen-2015-008417

- Prepublication history for this paper is available online. To view these files please visit the journal online (http://dx.doi.org/10.1136/ bmjopen-2015-008417).

Received 9 April 2015 Revised 9 June 2015 Accepted 22 June 2015

CrossMark

\footnotetext{
${ }^{1}$ Nutrition and Food safety Department, Zhejiang Provincial Center for Disease Control and Prevention, Hangzhou, China

${ }^{2}$ National Institute for Nutrition and Health, Beijing, China
}

Correspondence to Ronghua Zhang; zouyan910@yeah.net

\section{ABSTRACT}

Objectives: To explore the association of dietary behaviour factors on obesity among city, township and rural area adults.

Setting: A stratified cluster sampling technique was employed in the present cross-sectional study. On the basis of socioeconomic characteristics, two cities, two townships and two residential villages were randomly selected where the investigation was conducted.

Participants: A total of 1770 city residents, 2071 town residents and 1736 rural area residents participated in this survey.

Primary and secondary outcome measures: Dietary data were collected through interviews with each household member. Anthropometric values were measured. Participants with a body mass index (BMI) of $\geq 28.0 \mathrm{~kg} / \mathrm{m}^{2}$ were defined as obesity.

Results: The prevalence of obesity was 10.1\%, 7.3\% and $6.5 \%$ among city, township and rural area adults, respectively. Correlation analysis showed that for adults living in cities, the daily intake of rice and its products, wheat flour and its products, light coloured vegetables, pickled vegetables, nut, pork and sauce was positively correlated with BMI $(r=0.112,0.084,0.109,0.129$, $0.077,0.078,0.125, p<0.05$ ), while the daily intake of tubers, dried beans, milk and dairy products was negatively correlated with BMI $(r=-0.086,-0.078$, $-0.116, p<0.05$ ). For township residents, the daily intake of vegetable oil, salt, chicken essence, monosodium glutamate and sauce was positively correlated with BMI $(r=0.088,0.091,0.078,0.087$, $0.189, p<0.05)$. For rural area residents, the daily intake of pork, fish and shrimp, vegetable oil and salt was positively correlated with BMI ( $r=0.087,0.122$, $0.093,0.112, p<0.05$ ), while the daily intake of dark coloured vegetables was negatively correlated with BMI $(r=-0.105, p<0.05)$.

Conclusions: The prevalence of obesity was higher among city residents than among township and rural area residents. The findings of this study indicate that demographic and dietary factors could be associated with obesity among adults. Healthy dietary behaviour should be promoted and the ongoing monitoring of population nutrition and health status remains crucially important.

\section{Strengths and limitations of this study}

The present study is one of the few studies to examine the prevalence of obesity and its associated factors among city, township and rural area adults. Its strengths also include the large sample size and stratification of the analyses by region to observe the difference between a city, township and rural area. We were able to examine the association between a variety of demographic and dietary factors and body mass index. We had data on sociodemographic and dietary behaviour variables with which we were able to comprehensively analyse the difference among city, township and rural area adults.

- One limitation of the study is the cross-sectional design that disallows a sequence of temporality to be established for obesity and dietary behaviour. Residents with obesity may have changed their diet based on their clinician's suggestions. If they then ate a healthy diet, the dietary influence detected may be the result, but not the cause, of obesity. If it is true, then this healthy diet may in some cases drive the association to be null and make our findings under-reported. Future prospective cohort studies are warranted to verify our findings.

\section{INTRODUCTION}

Obesity represents a rapidly growing threat to the health of populations in an increasing number of countries. Indeed, they are now so common that they are replacing more traditional problems such as under nutrition and infectious diseases as the most significant causes of ill health. Between 1980 and 2008, the mean global body mass index (BMI) increased by $0.4-0.5 \mathrm{~kg} / \mathrm{m} 2$ per decade in men and women. ${ }^{1}$ Obesity is associated with the incidence of multiple comorbidities including type II diabetes, cancer and cardiovascular diseases. ${ }^{2}$ The worldwide prevalence has more than doubled since 1980. A number 
of studies have reported that with each surge in weight, there is an increase in the risks for coronary heart disease, type 2 diabetes, cancers (endometrial, breast and colon), hypertension, dyslipidaemia, stroke, sleep apnoea, respiratory problems, osteoarthritis and gynaecological problems. ${ }^{3}$ The trend in the rising prevalence of obesity and related morbidity and mortality in developing countries has been attributed to rapid urbanisation, nutrition transition and reduced physical activity. ${ }^{4}$

China has had a history of under-nutrition followed by the most rapid increase in obesity and related diseases worldwide, with differential rates across rural and urban areas. ${ }^{5}$ Owing to various factors such as geographical environment, living habits and dietary behaviour, people in different regions have different epidemic characteristics and dietary behaviour, which may be associated with the risk of obesity. The aim of this study was to explore the association between a variety of demographic and dietary behaviour factors and obesity among city, township and rural area adults.

\section{SUBJECTS AND METHODS Subjects}

A stratified cluster sampling technique was employed in this cross-sectional study. On the basis of socioeconomic characteristics, two cities, two townships and two residential villages were randomly selected where the investigation was conducted. The city is defined as the centre area of the big city, and the township is defined as all the district and county cities. The residential village is defined as a county. In every sampling unit, 450 households were selected by the random sampling method according to the household registration information. Then every member of the sampled household was interviewed.

\section{METHODS}

During home visits spanning $3 \mathrm{~d}$, dietary data were collected through interviews with each household member, including rice and its products, wheat flour and its products, tuber, bean products, dark coloured vegetables, light coloured vegetables, pickled vegetables, pork, poultry, milk and dairy products, eggs, fish and shrimp, vegetable oil, sugar and starch, salt, chicken essence, monosodium glutamate and sauce. The questionnaire was administrated face to face by trained staff through door to door interview. Information about other covariables was also collected including educational level, physical activity level, smoking, drinking and lifestyle. All subjects provided written informed consent after the research protocols were carefully explained to them.

\section{Anthropometric measurements}

Height was measured without shoes to the nearest $0.2 \mathrm{~cm}$ using a portable SECA stadiometer, and weight was measured without shoes and in light clothing to the nearest $0.1 \mathrm{~kg}$ on a calibrated beam scale. Waist circumference was measured at a point immediately above the iliac crest on the midaxillary line at minimal respiration to the nearest $0.1 \mathrm{~cm} .{ }^{6}$ BMI was calculated by weight $(\mathrm{kg}) /$ height $(\mathrm{m})^{2}$. Participants with a BMI of $\geq 28.0 \mathrm{~kg} / \mathrm{m}^{2}$ were defined as obese. ${ }^{7}$

\section{Statistical analysis}

As continuous variables were not normally distributed, they were described as the median, 25th and 75th centiles. The differences between rural residents and urban residents were evaluated by nonparametric test (Mann-Whitney test). The distributions of potential influencing factor proportions were compared by the $\chi^{2}$ test. Spearman correlations were used to explore the correlations between dietary factors and BMI. Spearman's $r$ was used to describe the strength of the relationship between two variables. Data processing and statistical analyses were performed using the SAS 9.2 software. All tests were two sided and the level of significance was set at $\mathrm{p}<0.05$.

\section{RESULTS}

\section{Demographic and dietary intake characteristics}

A total of 1770 city residents, 2071 town residents and 1736 rural area residents participated in this survey. The prevalence of obesity was $10.1 \%, 7.3 \%$ and $6.5 \%$ in city, township and rural area adults, respectively $\left(\chi^{2}=15.656\right.$, $\mathrm{p}=0.000)$. The median value (25th, 75th centile) of BMI was 23.0 (20.2, 25.3), 22.2 (19.6, 24.7), 21.6 (19.1, 24.1) among adults in the three types of region, respectively $(\mathrm{H}=97.749$, $\mathrm{p}=0.000)$.

The demographic and dietary intake characteristics are presented in table 1 . When the demographic and dietary intake variables were stratified by region, there were significant difference on BMI, weight, waist circumstance among city, township and rural area adults with the same direction $(p<0.05)$. Among city residents, the intake of rice and its products and pickled vegetables was higher in obese adults than in non-obese adults $(p<0.05)$. Among township residents, wheat flour and its products, salt and monosodium glutamate were higher in obese adults than in non-obese adults $(\mathrm{p}<0.05)$. There were no significant differences in dietary intake among rural area adults.

Demographic characteristics and dietary behaviour distribution are presented in table 2. Among city residents, the distributions of education level, number of family members living together, drinking high alcohol liquor and drinking Yellow Wine were significant between obese adults and non-obese adults $(p<0.05)$. Among township and rural area residents, there were no significant differences in the distribution of these covariables $(\mathrm{p}>0.05)$.

\section{Correlations between dietary factors}

Correlation analysis showed that for adults living in cities, the daily intake of rice and its products, wheat 


\begin{tabular}{|c|c|c|c|c|c|c|c|c|c|c|c|c|c|c|c|c|c|c|c|c|c|c|c|c|}
\hline \multirow{3}{*}{$\begin{array}{l}\text { Demographic } \\
\text { characteristics }\end{array}$} & \multicolumn{8}{|l|}{ City } & \multicolumn{8}{|c|}{ Township } & \multicolumn{8}{|c|}{ Rural area } \\
\hline & \multicolumn{3}{|c|}{ Obese $(\mathrm{N}=178)$} & \multicolumn{3}{|c|}{ Non-obese (N=1592) } & \multirow[b]{2}{*}{$\mathbf{z}$} & \multirow[b]{2}{*}{$p$ Value } & \multicolumn{3}{|c|}{ Obese $(\mathrm{N}=152)$} & \multicolumn{3}{|c|}{ Non-obese (N=1919) } & \multirow[b]{2}{*}{$\mathbf{z}$} & \multirow[b]{2}{*}{$\mathrm{p}$ Value } & \multicolumn{3}{|c|}{ Obese $(\mathrm{N}=113)$} & \multicolumn{3}{|c|}{ Non-obese $(\mathrm{N}=1623)$} & \multirow[b]{2}{*}{ z } & \multirow[b]{2}{*}{ p Value } \\
\hline & Median & $25 \%$ & $75 \%$ & Median & $25 \%$ & $75 \%$ & & & Median & $25 \%$ & $75 \%$ & Median & $25 \%$ & $75 \%$ & & & Median & $25 \%$ & $75 \%$ & Median & $25 \%$ & $75 \%$ & & \\
\hline Age (years) & 57.8 & 46.5 & 65.1 & 57.2 & 45.1 & 65.7 & 0.287 & 0.774 & 49.8 & 41.0 & 60.0 & 53.6 & 42.6 & 62.6 & -2.109 & 0.035 & 49.0 & 41.0 & 57.0 & 50.0 & 42.0 & 60.0 & -1.258 & 0.209 \\
\hline Weight (kg) & 74.9 & 69.1 & 84.0 & 60.0 & 53.5 & 66.6 & 17.002 & 0.000 & 77.5 & 72.2 & 84.7 & 58.4 & 52.2 & 65.0 & 17.728 & 0.000 & 78.7 & 69.4 & 85.7 & 56.5 & 50.3 & 63.2 & 15.740 & 0.000 \\
\hline Height $(\mathrm{cm})$ & 159.2 & 153.7 & 166.7 & 161.0 & 156.0 & 167.0 & -2.567 & 0.010 & 161.3 & 155.0 & 167.6 & 160.5 & 155.0 & 166.4 & 0.839 & 0.401 & 161.0 & 153.7 & 168.7 & 159.4 & 153.9 & 165.6 & 1.137 & 0.256 \\
\hline BMI (kgm-2) & 29.3 & 28.6 & 30.5 & 23.3 & 21.2 & 25.1 & 21.910 & 0.000 & 29.5 & 28.6 & 30.9 & 22.7 & 20.8 & 24.7 & 20.551 & 0.000 & 29.5 & 28.6 & 30.8 & 22.2 & 20.2 & 24.2 & 17.798 & 0.000 \\
\hline Waist circumference $(\mathrm{cm})$ & 97.0 & 90.1 & 101.5 & 81.9 & 75.0 & 88.9 & 16.354 & 0.000 & 98.5 & 94.2 & 101.9 & 80.7 & 74.9 & 86.5 & 18.283 & 0.000 & 97.1 & 92.4 & 101.2 & 77.3 & 71.5 & 84.1 & 15.139 & 0.000 \\
\hline \multicolumn{25}{|l|}{ Dietary intakes } \\
\hline Energy intake(kcal) & 1786.8 & 1349.4 & 2197.6 & 1607.5 & 1232.0 & 2144.5 & 1.126 & 0.260 & 2322.2 & 1742.7 & 2866.4 & 2167.7 & 1743.4 & 2694.4 & 1.159 & 0.246 & 1837.8 & 1581.5 & 2159.1 & 1829.7 & 1471.2 & 2259.7 & 0.435 & 0.664 \\
\hline Rice and its products (g) & 216.7 & 164.6 & 292.9 & 200.0 & 135.8 & 258.3 & 2.344 & 0.019 & 225.7 & 154.1 & 309.3 & 232.8 & 167.9 & 317.6 & -0.807 & 0.420 & 166.7 & 115.7 & 243.3 & 189.0 & 132.5 & 266.7 & -1.646 & 0.100 \\
\hline $\begin{array}{l}\text { Wheat flour and its } \\
\text { products (g) }\end{array}$ & 66.7 & 36.7 & 130.8 & 66.7 & 30.5 & 100.0 & 1.747 & 0.081 & 66.3 & 27.2 & 109.4 & 41.8 & 3.7 & 82.9 & 2.463 & 0.014 & 42.8 & 19.5 & 95.9 & 53.4 & 32.8 & 86.7 & -1.131 & 0.258 \\
\hline Bean products (g) & 7.7 & 0.0 & 15.6 & 7.7 & 1.3 & 15.8 & 0.283 & 0.777 & 15.4 & 4.6 & 28.9 & 13.1 & 3.6 & 26.9 & 0.716 & 0.474 & 13.7 & 7.7 & 27.0 & 16.9 & 7.7 & 33.2 & -0.525 & 0.599 \\
\hline Dark colored vegetables ( $\mathrm{g}$ ) & 76.1 & 26.3 & 147.5 & 81.7 & 43.3 & 133.8 & -0.728 & 0.467 & 70.0 & 33.3 & 130.0 & 66.7 & 31.7 & 108.3 & 0.751 & 0.452 & 56.7 & 26.7 & 91.5 & 66.7 & 33.3 & 100.0 & -1.729 & 0.084 \\
\hline $\begin{array}{l}\text { Light coloured } \\
\text { vegetables (g) }\end{array}$ & 202.9 & 127.2 & 255.0 & 161.7 & 104.3 & 236.2 & 1.859 & 0.063 & 140.0 & 98.3 & 240.0 & 146.7 & 96.7 & 222.5 & 0.072 & 0.943 & 167.0 & 99.2 & 215.0 & 160.0 & 106.7 & 230.7 & -0.254 & 0.799 \\
\hline Pickled vegetables (g) & 1.7 & 1.7 & 13.3 & 0.0 & 0.0 & 6.7 & 2.674 & 0.007 & 6.7 & 0.0 & 11.7 & 0.0 & 0.0 & 11.5 & 1.215 & 0.224 & 18.3 & 7.9 & 39.2 & 16.7 & 9.7 & 38.7 & -0.106 & 0.916 \\
\hline Pork (g) & 43.3 & 17.9 & 96.8 & 47.3 & 20.0 & 86.7 & -0.142 & 0.887 & 53.1 & 25.0 & 75.0 & 46.7 & 16.7 & 83.3 & 0.579 & 0.563 & 95.0 & 55.4 & 137.5 & 73.3 & 41.0 & 120.0 & 1.938 & 0.053 \\
\hline Poultry (g) & 16.7 & 0.0 & 50.0 & 10.0 & 0.0 & 40.8 & 0.663 & 0.508 & 6.6 & 0.0 & 33.3 & 10.0 & 0.0 & 41.7 & -0.836 & 0.403 & 50.0 & 33.3 & 86.7 & 53.3 & 33.3 & 80.0 & 0.336 & 0.737 \\
\hline Milk and dairy products (g) & 0.0 & 0.0 & 13.9 & 0.0 & 0.0 & 83.3 & -1.841 & 0.066 & 0.0 & 0.0 & 0.0 & 0.0 & 0.0 & 0.0 & -0.454 & 0.650 & 66.7 & 136.0 & 205.3 & 65.4 & 86.1 & 152.9 & 0.391 & 0.696 \\
\hline Eggs (g) & 21.9 & 0.0 & 51.7 & 20.0 & 0.0 & 43.3 & 0.506 & 0.613 & 20.0 & 3.3 & 36.8 & 16.7 & 0.0 & 33.3 & 1.421 & 0.155 & 23.3 & 16.7 & 37.5 & 23.3 & 16.7 & 40.0 & 0.021 & 0.984 \\
\hline Fish and shrimp (g) & 68.3 & 23.8 & 122.5 & 68.3 & 33.7 & 120.3 & -0.431 & 0.666 & 18.3 & 0.0 & 56.7 & 22.0 & 0.0 & 57.2 & -0.663 & 0.507 & 76.7 & 38.3 & 134.2 & 60.0 & 33.3 & 93.3 & 1.622 & 0.105 \\
\hline Vegetable oil (g) & 29.9 & 10.8 & 43.8 & 30.0 & 19.6 & 44.6 & -0.829 & 0.407 & 39.0 & 27.6 & 69.4 & 37.9 & 25.1 & 56.4 & 1.062 & 0.288 & 37.7 & 18.5 & 62.8 & 32.9 & 19.5 & 52.7 & 0.708 & 0.479 \\
\hline Sugar and starch (g) & 3.1 & 0.0 & 13.3 & 2.4 & 0.0 & 7.2 & 1.094 & 0.274 & 0.1 & 0.0 & 7.3 & 1.4 & 0.0 & 6.8 & -0.614 & 0.539 & 2.8 & 1.2 & 5.7 & 3.4 & 1.5 & 7.8 & -0.997 & 0.319 \\
\hline Salt (g) & 6.6 & 4.4 & 11.2 & 6.3 & 4.0 & 10.3 & 0.652 & 0.514 & 9.4 & 6.4 & 13.2 & 7.7 & 5.1 & 11.0 & 2.493 & 0.013 & 11.4 & 6.9 & 16.4 & 9.2 & 5.8 & 14.3 & 1.712 & 0.087 \\
\hline Chicken essence (g) & 10.2 & 2.9 & 24.6 & 8.7 & 3.4 & 19.4 & 0.711 & 0.477 & 5.9 & 1.1 & 19.2 & 7.1 & 0.7 & 15.2 & 0.616 & 0.538 & 3.5 & 1.8 & 5.2 & 2.4 & 1.3 & 3.3 & 1.525 & 0.127 \\
\hline Monosodium glutamate ( $\mathrm{g}$ ) & 1.9 & 0.0 & 4.6 & 1.9 & 0.0 & 4.2 & 0.291 & 0.771 & 3.4 & 1.2 & 5.5 & 1.9 & 0.3 & 3.8 & 2.683 & 0.007 & 2.5 & 1.4 & 5.3 & 3.0 & 1.6 & 5.1 & -0.645 & 0.519 \\
\hline Sauce $(g)$ & 5.6 & 2.4 & 11.4 & 7.2 & 3.4 & 13.9 & -2.283 & 0.023 & 9.0 & 3.8 & 17.8 & 6.5 & 2.2 & 13.8 & 2.282 & 0.023 & 6.7 & 3.9 & 13.4 & 5.4 & 2.6 & 9.6 & 1.447 & 0.148 \\
\hline
\end{tabular}


Table 2 Demographic characteristics and dietary behaviour in adults, Zhejiang province, China

\begin{tabular}{|c|c|c|c|c|c|c|c|c|c|c|c|c|c|c|c|c|c|c|}
\hline \multirow[b]{3}{*}{ Characteristic } & \multicolumn{6}{|l|}{ City } & \multicolumn{6}{|c|}{ Township } & \multicolumn{6}{|c|}{ Rural area } \\
\hline & \multicolumn{2}{|c|}{ Obese } & \multicolumn{2}{|c|}{ Non-obese } & \multirow[b]{2}{*}{$x^{2}$} & \multirow[b]{2}{*}{ p Value } & \multicolumn{2}{|c|}{ Obese } & \multicolumn{2}{|c|}{ Non-obese } & \multirow[b]{2}{*}{$x^{2}$} & \multirow[b]{2}{*}{ p Value } & \multicolumn{2}{|c|}{ Obese } & \multicolumn{2}{|c|}{ Non-obese } & \multirow[b]{2}{*}{$\chi^{2}$} & \multirow[b]{2}{*}{ p Value } \\
\hline & $\overline{\mathbf{N}}$ & $\%$ & $\mathbf{N}$ & $\%$ & & & $\mathbf{N}$ & $\%$ & $\overline{\mathbf{N}}$ & $\%$ & & & $\overline{\mathbf{N}}$ & $\%$ & $\overline{\mathbf{N}}$ & $\%$ & & \\
\hline \multicolumn{19}{|l|}{ Gender } \\
\hline Male & 73 & 9.8 & 672 & 90.2 & 0.052 & 0.820 & 78 & 8.0 & 902 & 92.0 & 1.051 & 0.305 & 53 & 6.5 & 757 & 93.5 & 0.003 & 0.957 \\
\hline Female & 105 & 10.2 & 920 & 89.8 & & & 74 & 6.8 & 1017 & 93.2 & & & 60 & 6.5 & 866 & 93.5 & & \\
\hline \multicolumn{19}{|l|}{ Education level } \\
\hline Not going to school & 13 & 15.3 & 72 & 84.7 & 26.267 & 0.000 & 2 & 2.9 & 67 & 97.1 & 8.413 & 0.209 & 5 & 10.4 & 43 & 89.6 & 5.286 & 0.508 \\
\hline Illiteracy & 13 & 19.1 & 55 & 80.9 & & & 23 & 7.0 & 305 & 93.0 & & & 13 & 5.8 & 211 & 94.2 & & \\
\hline Primary school & 59 & 13.9 & 365 & 86.1 & & & 52 & 7.8 & 613 & 92.2 & & & 40 & 5.6 & 678 & 94.4 & & \\
\hline Junior middle school & 42 & 7.7 & 506 & 92.3 & & & 60 & 8.6 & 639 & 91.4 & & & 45 & 8.1 & 512 & 91.9 & & \\
\hline Senior middle school & 28 & 8.5 & 303 & 91.5 & & & 10 & 4.3 & 220 & 95.7 & & & 7 & 4.9 & 135 & 95.1 & & \\
\hline Junior college & 16 & 10.7 & 134 & 89.3 & & & 4 & 7.4 & 50 & 92.6 & & & 2 & 8.0 & 23 & 92.0 & & \\
\hline University or above & 7 & 4.3 & 157 & 95.7 & & & 1 & 3.8 & 25 & 96.2 & & & 1 & 4.5 & 21 & 95.5 & & \\
\hline \multicolumn{19}{|l|}{ Marital status } \\
\hline Single & 10 & 11.1 & 80 & 88.9 & 2.877 & 0.411 & 8 & 10.0 & 72 & 90.0 & 4.536 & 0.209 & 3 & 3.7 & 81 & 96.4 & 4.208 & 0.24 \\
\hline Has a spouse & 152 & 10.0 & 1371 & 90.0 & & & 138 & 7.3 & 1746 & 92.7 & & & 102 & 6.6 & 1443 & 93.4 & & \\
\hline Divorced & 1 & 3.1 & 31 & 96.9 & & & 2 & 22.2 & 7 & 77.8 & & & 0 & 0.0 & 15 & 100.0 & & \\
\hline Widowed & 15 & 12.0 & 110 & 88.0 & & & 4 & 4.1 & 94 & 95.9 & & & 8 & 9.1 & 84 & 91.3 & & \\
\hline Number of family members & living & ogeth & & & & & & & & & & & & & & & & \\
\hline Less than 4 & 130 & 8.9 & 1332 & 91.1 & 12.597 & 0.000 & 105 & 7.0 & 1395 & 93.0 & 0.8 & 0.387 & 83 & 7.2 & 1084 & 92.9 & 2.228 & 0.136 \\
\hline Equal to or more than 4 & 48 & 15.6 & 260 & 84.4 & & & 47 & 8.2 & 524 & 91.8 & & & 30 & 5.3 & 539 & 94.7 & & \\
\hline Smoke & & & & & & & & & & & & & & & & & & \\
\hline Do not smoke & 148 & 10.4 & 1272 & 89.6 & 7.636 & 0.054 & 117 & 7.7 & 1402 & 92.3 & 2.025 & 0.567 & 81 & 6.3 & 1207 & 93.7 & 0.787 & 0.852 \\
\hline Smoke every day & 24 & 8.2 & 269 & 91.8 & & & 33 & 6.6 & 465 & 93.4 & & & 28 & 7.0 & 370 & 93.0 & & \\
\hline Not smoking every day & 6 & 18.2 & 27 & 81.8 & & & 2 & 3.8 & 51 & 96.2 & & & 4 & 8.3 & 44 & 91.7 & & \\
\hline I do not know & 0 & 0.0 & 24 & 100.0 & & & 0 & 0.0 & 1 & 100.0 & & & 0 & 0.0 & 2 & 100.0 & & \\
\hline Drinking low alcohol liquor & & & & & & & & & & & & & & & & & & \\
\hline No & 147 & 9.6 & 1393 & 90.5 & 3.059 & 0.08 & 131 & 7.1 & 1711 & 92.9 & 1.264 & 0.261 & 93 & 6.6 & 1318 & 93.4 & 0.085 & 0.771 \\
\hline Yes & 31 & 13.5 & 199 & 86.5 & & & 21 & 9.2 & 208 & 90.8 & & & 20 & 6.2 & 305 & 93.8 & & \\
\hline Drinking high alcohol liquor & & & & & & & & & & & & & & & & & & \\
\hline No & 153 & 9.4 & 1484 & 90.7 & 11.063 & 0.001 & 129 & 7.0 & 1716 & 93.0 & 2.995 & 0.084 & 103 & 6.5 & 1471 & 93.5 & 0.034 & 0.854 \\
\hline Yes & 25 & 18.8 & 108 & 81.2 & & & 23 & 10.2 & 203 & 89.8 & & & 10 & 6.2 & 152 & 93.8 & & \\
\hline Drinking yellow wine & & & & & & & & & & & & & & & & & & \\
\hline No & 161 & 9.7 & 1504 & 90.3 & 4.092 & 0.043 & 131 & 7.0 & 1745 & 93.0 & 3.714 & 0.054 & 108 & 6.5 & 1565 & 93.5 & 0.042 & 0.837 \\
\hline Yes & 17 & 16.3 & 88 & 83.8 & & & 21 & 10.8 & 174 & 89.2 & & & 5 & 7.9 & 58 & 92.1 & & \\
\hline Drinking beer & & & & & & & & & & & & & & & & & & \\
\hline No & 141 & 9.8 & 1294 & 90.2 & 0.459 & 0.498 & 114 & 7.1 & 1485 & 92.9 & 0.45 & 0.502 & 85 & 7.1 & 1115 & 92.9 & 2.129 & 0.145 \\
\hline Yes & 37 & 11.1 & 298 & 89.0 & & & 38 & 8.1 & 434 & 91.9 & & & 28 & 5.2 & 508 & 94.8 & & \\
\hline Drinking wine & & & & & & & & & & & & & & & & & & \\
\hline No & 153 & 10.0 & 1386 & 90.1 & 0.098 & 0.755 & 141 & 7.3 & 1783 & 92.7 & 0.005 & 0.946 & 109 & 6.5 & 1567 & 93.5 & 0.002 & 0.961 \\
\hline Yes & 25 & 10.9 & 206 & 89.2 & & & 11 & 7.5 & 136 & 92.5 & & & 4 & 6.7 & 56 & 93.3 & & \\
\hline
\end{tabular}


flour and its products, light coloured vegetables, pickled vegetables, nut, pork and sauce was positively correlated with BMI ( $\mathrm{r}=0.112,0.084,0.109,0.129,0.077,0.078$, $0.125, \mathrm{p}<0.05)$, while the daily intake of tubers, dried beans, milk and dairy products was negatively correlated with BMI $(\mathrm{r}=-0.086,-0.078,-0.116, \mathrm{p}<0.05)$. For township residents, the daily intake of vegetable oil, salt, chicken essence, monosodium glutamate and sauce was positively correlated with BMI ( $\mathrm{r}=0.088,0.091,0.078$, $0.087,0.189, \mathrm{p}<0.05)$. For rural area residents, the daily intake of pork, fish and shrimp, vegetable oil and salt was positively correlated with BMI ( $\mathrm{r}=0.087,0.122,0.093$, $0.112, \mathrm{p}<0.05)$, while the daily intake of dark coloured vegetables was negatively correlated with BMI $(r=-0.105$, $\mathrm{p}<0.05)$ (table 3).

\section{DISCUSSION}

This study employed an analytical approach that provides insight into two types of commonly recognised risk factors for adult obesity-demographic and dietary factors.

In recent decades, the double burden of malnutrition -the coexistence of under-nutrition and over-nutrition in the same population-has become a prominent public health concern in transitional countries. Traditional diet has been replaced by the 'Western diet' and major declines in all phases of activity and increased sedentary activity as the main reasons explaining the rapid increase in overweight and obesity, bring major economic and health costs. ${ }^{8-10}$

According to a study carried out among Chinese urban children and adolescents (aged 7-18 years) in 2000 , the prevalence of obesity in boys was $6.5 \%$ in Beijing, $4.9 \%$ in Shanghai, $4.5 \%$ in coastal big cities, and $2.0 \%$ in coastal medium/small-sized cities, respectively, while the prevalence of obesity and overweight in girls of the same age group was $3.7 \%$ in Beijing, $2.6 \%$ in Shanghai, $2.8 \%$ in coastal big cities, and $1.7 \%$ in coastal medium/small-sized cities, respectively. ${ }^{11}$ The China Health and Nutrition Surveys reported that the prevalence of obesity in children aged 7-17 increased from $5.2 \%$ in 1991 to $13.2 \%$ in 2006 , and the most noticeable increase was in children from urban areas and those from higher income backgrounds. ${ }^{12}$ In our study, the prevalence of obesity reached $10.1 \%, 7.3 \%$ and $6.5 \%$ among city, township and rural area adults in Zhejiang province. The prevalence of obesity in the coastal big cities, followed by that in the township cities, had reached the average level of the developed countries, and the result was consistent with Ji CY's study. ${ }^{13} \mathrm{Ji} \mathrm{CY}$ also reported that the prevalence of obesity was low in most of the inland cities at an early stage of epidemic overweight. The epidemic manifested a gradient distribution in groups, which was closely related to the socioeconomic status of the populations. ${ }^{13}$ This was also

Table 3 Correlations between BMI and daily dietary intake among adults living in cities, townships and rural area, Zhejiang province, China

\begin{tabular}{|c|c|c|c|c|c|c|}
\hline & \multicolumn{2}{|l|}{ City } & \multicolumn{2}{|l|}{ Township } & \multicolumn{2}{|c|}{ Rural area } \\
\hline & $\bar{r}$ & p Value & $\bar{r}$ & p Value & $\overline{\mathbf{r}}$ & p Value \\
\hline \multicolumn{7}{|l|}{ Food } \\
\hline Wheat flour and its products (g) & $0.084^{*}$ & 0.030 & 0.008 & 0.818 & 0.033 & 0.567 \\
\hline Tubers $(\mathrm{g})$ & $-0.086^{\star}$ & 0.027 & 0.025 & 0.476 & -0.030 & 0.671 \\
\hline Dried beans $(\mathrm{g})$ & $-0.078^{*}$ & 0.044 & -0.002 & 0.951 & -0.094 & 0.374 \\
\hline Light coloured vegetables (g) & $0.109^{\star *}$ & 0.005 & 0.019 & 0.582 & -0.027 & 0.474 \\
\hline Pickled vegetables $(\mathrm{g})$ & $0.129^{\star *}$ & 0.001 & 0.057 & 0.100 & -0.106 & 0.207 \\
\hline Fruits $(g)$ & -0.024 & 0.544 & 0.053 & 0.121 & 0.130 & 0.174 \\
\hline Nut $(g)$ & $0.077^{\star}$ & 0.046 & 0.041 & 0.233 & 0.023 & 0.814 \\
\hline Pork (g) & $0.078^{*}$ & 0.043 & 0.018 & 0.596 & $0.087^{*}$ & 0.030 \\
\hline Vegetable oil $(\mathrm{g})$ & -0.036 & 0.347 & $0.088^{*}$ & 0.011 & $0.093^{*}$ & 0.019 \\
\hline Sugar and starch (g) & 0.002 & 0.969 & 0.035 & 0.304 & -0.063 & 0.330 \\
\hline Salt (g) & 0.002 & 0.966 & $0.091^{\star *}$ & 0.008 & $0.112^{\star \star}$ & 0.004 \\
\hline Chicken essence $(\mathrm{g})$ & 0.020 & 0.608 & $0.078^{*}$ & 0.024 & 0.124 & 0.165 \\
\hline Monosodium glutamate (g) & -0.009 & 0.813 & $0.087^{*}$ & 0.011 & 0.049 & 0.268 \\
\hline Sauce $(g)$ & $0.125^{\star *}$ & 0.001 & $0.189^{* *}$ & 0.000 & 0.052 & 0.237 \\
\hline
\end{tabular}


consistent with the previous report that a higher prevalence of obesity was observed in the more educated, urban, high income and high social status segments of society. ${ }^{14-17}$ Recently, in Drewnowski A's study, census tract level home values and college education were more strongly associated with obesity than household incomes. For each additional $\$ 100000$ in median home values, the census tract obesity prevalence was $2.3 \%$ lower. The three socioeconomic status factors together explained $70 \%$ of the variance in census tract obesity prevalence. ${ }^{18}$

There was a pattern that the risk of obesity was greater among city residents with higher education. It seems possible that the education level may be complicating the relationship between dietary behaviour and obesity. On the one hand, residents with a higher education level are more likely to endorse health ideals such as a more healthy diet or physical activities to preserve a good body image, ${ }^{19}$ and linked to a lower prevalence of obesity among city residents, and the result was consistent with previous studies. ${ }^{20-21}$ On the other hand, a higher education level may be associated with clerical work or increased sitting time among township residents and rural residents, which one might expect would increase the risk of obesity; thus, we could not find the effect of education level on the risk of obesity in a township and rural area. In addition, this inconsistency between city and township residents and rural area residents was similar to the opinion that an initial increase from low social economic status to mid-level social economic status was associated with worse health outcomes and behaviours; however, the continued increase from mid-social economic status to high social economic status saw returns to healthy outcomes and behaviours. ${ }^{22}$

The major finding of dietary factors among city residents was that residents with obesity have a higher daily intake of rice and its products and pickled vegetables. BMI increased with the daily intake of rice and its products, wheat flour and its products, light coloured vegetables, pickled vegetables, nut, pork and sauce and decreased with the daily intake of tubers, dried beans, milk and dairy products. In a township, residents with obesity have a higher daily intake of vegetable oil, salt, chicken essence, monosodium glutamate and sauce. The major finding among rural area residents was that BMI increased with the daily intake of pork, fish and shrimp, vegetable oil and salt, but decreased with the daily intake of dark coloured vegetables. The differences in relationship between dietary factors and BMI among city, township and rural area residents may be due to the different dietary patterns, as reported in the literature, ${ }^{23}$ but a daily intake of salt and foods high in salt and sugar such as sauce, chicken essence and pickled vegetables was associated with high BMI. This was consistent with the ecological study of the UK and other previous studies. ${ }^{24-26}$ Also, a Swiss study found a positive association between obesity and salt intake. ${ }^{27}$ This was also consistent with the policy and action on nutrition and health promotion in many countries. In the UK, a wide range of policies are in place, including support for breastfeeding and healthy weaning practices, nutritional standards in schools, restrictions on marketing foods high in fat, sugar and salt to children, schemes to boost participation in sport, active travel plans, and weight management services. ${ }^{28-29}$ In recent years, there has been increased interest in the public health benefit of small changes to behaviours. The developing world needs to give far greater emphasis to addressing the prevention of the adverse health consequences of this shift to the nutrition transition stage.

Among city residents, the daily intake of milk and dairy products was associated with low BMI; this result was similar to the results of a random-sample population-based study in Córdoba, Argentina. ${ }^{30}$ Among rural residents, the daily intake of dark coloured vegetables was associated with low BMI, while the daily intake of vegetable oil was associated with high BMI. The obesity problem needs to be tackled differently in the city, township and rural area as their correlated dietary factors are not the same.

In conclusion, this study extends our understanding of demographic and dietary influencing factors on obesity among city, township and rural area residents. Obesity is still highly prevalent among Chinese adults. The prevalence of obesity was higher in city residents than in township and rural area residents. Our results call for urgent action to educate people in diet style modifications and the need for effective preventive and educational strategies on obesity.

Contributors RZ, YZ and GD were responsible for the study design. $\mathrm{YZ}$ was responsible for the analysis, paper writing and revision. RZ, BZ, FG, JC, LH, $\mathrm{HZ}$ and $\mathrm{YF}$ took part in the field investigation and data collection. BZ, LH, HZ and YF were in charge of laboratory detection. All authors contributed to the discussion and interpretation of the data and to the writing of the manuscript.

Funding This research received no specific grant from any funding agency in the public, commercial or not-for-profit sectors.

Competing interests None declared.

Patient consent Obtained.

Ethics approval The study protocol was approved by the ethics committee of Zhejiang provincial center for disease control and prevention.

Provenance and peer review Not commissioned; externally peer reviewed.

Data sharing statement No additional data are available.

Open Access This is an Open Access article distributed in accordance with the Creative Commons Attribution Non Commercial (CC BY-NC 4.0) license, which permits others to distribute, remix, adapt, build upon this work noncommercially, and license their derivative works on different terms, provided the original work is properly cited and the use is non-commercial. See: http:// creativecommons.org/licenses/by-nc/4.0/

\section{REFERENCES}

1. Finucane MM, Stevens GA, Cowan MJ, et al. National, regional, and global trends in body mass index since 1980: systematic analysis of health examination surveys and epidemiological studies with 960 country-years and 9.1 million participants. Lancet 2011;377:557-67.

2. Guh DP, Zhang W, Bansback N, et al. The incidence of co-morbidities related to obesity and overweight: a systematic review and meta-analysis. BMC Public Health 2009;9:88. 
3. Centers for Disease Control and Prevention, "Overweight and obesity 2012," 2013. http://www.cdc.gov/obesity/adult/causes/index.html

4. Misra A, Khurma L. Obesity and the metabolic syndrome in developing countries. J Clin Endocrinol Metab 2008;93:s9-s30.

5. Van de Poel E, O'Donnell O, Van Doorslaer E. Are urban children really healthier? Evidence from 47 developing countries. Soc Sci Med 2007;65:1986-2003.

6. Chumlea NC, Kuczmarski RJ. Using a bony landmark to measure waist circumference. J Am Diet Assoc 1995;95:12.

7. Centers for Disease Control and Prevention (updated 2012) Defining Overweight and Obesity. http://www.cdc.gov/obesity/defining.html (accessed Sep 2012).

8. Popkin BM, Du S, Zhai F, et al. Cohort Profile: The China Health and Nutrition Survey-monitoring and understanding socio-economic and health change in China, 1989-2011. Int J Epidemiol 2010;39:1435-40.

9. Du H, Bennett D, Li L, et al. Physical activity and sedentary leisure time and their associations with BMI, waist circumference, and percentage body fat in 0.5 million adults: the China Kadoorie Biobank study. Am J Clin Nutr 2013;97:487-96.

10. Popkin BM, Adair LS, Ng SW. Global nutrition transition and the pandemic of obesity in developing countries. Nutr Rev 2012;70:3-21.

11. Ji CY, Working Group on Obesity in China (WGOC). Report on childhood obesity in China (4) prevalence and trends of overweight and obesity in Chinese urban school-age children and adolescents, 1985-2000. Biomed Environ Sci 2007;20:1-10.

12. Cui Z, Huxley R, Wu Y, et al. Temporal trends in overweight and obesity of children and adolescents from nine Provinces in China from 1991-2006. Int J Pediatr Obes 2010;5:365-74.

13. Ji CY, Cooperative Study on Childhood Obesity, Working Group on Obesity in China (WGOC). The prevalence of childhood overweight/ obesity and the epidemic changes in 1985-2000 for Chinese schoolage children and adolescents. Obes Rev 2008;9(Suppl 1):78-81.

14. De Silva A, De Silva S, Haniffa R, et al. A cross sectional survey on social, cultural and economic determinants of obesity in a low middle income setting. Int $J$ Equity Health 2015;14:6.

15. Taylor R, Badcock J, King H, et al. Dietary intake, exercise, obesity and non-communicable disease in rural and urban populations of three Pacific Island countries. J Am Coll Nutr 1992;11:283-93.

16. Wang $\mathrm{Y}, \mathrm{Mi}$ J, Shan $\mathrm{XY}$, et al. Is China facing an obesity epidemic and the consequences? The trends in obesity and chronic disease in China. Int J Obes (Lond) 2007;31:177-88.

17. Janghorbani $M$, Amini $M$, Willett WC, et al. First nationwide survey of prevalence of overweight, underweight, and abdominal obesity in Iranian adults. Obesity (Silver Spring) 2007;15:2797-808.
18. Drewnowski A, Rehm CD, Arterburn D. The geographic distribution of obesity by census tract among 59767 insured adults in King County, WA. Int J Obes (Lond) 2014;38:833-9.

19. Ziraba AK, Fotso JC, Ochako R. Overweight and obesity in urban Africa: a problem of the rich or the poor? BMC Public Health 2009;9:465.

20. Zeki A, Hazzouri A, Haan MN, et al. Associations of intergenerational education with metabolic health in US Latinos. Obesity (Silver Spring) 2015;23:1097-104

21. Andreenko E, Mladenova S, Akabaliev V. Anthropometric obesity indices in relation to age, educational level, occupation and physical activity in Bulgarian men. Nutr Hosp 2014;31:658-65.

22. Nguyen AB, Moser R, Chou WY. Race and health profiles in the United States: an examination of the social gradient through the 2009 CHIS adult survey. Public Health 2014;128:1076-86.

23. Reynolds K, Gu D, Whelton PK, et al. Prevalence and risk factors of overweight and obesity in China. Obesity (Silver Spring) 2007;15:10-18.

24. Siervo M, Montagnese C, Mathers JC, et al. Sugar consumption and global prevalence of obesity and hypertension: an ecological analysis. Public Health Nutr 2014;17:587-96.

25. Arora NK, Pillai R, Dasgupta R, et al. Whole-of-society monitoring framework for sugar, salt, and fat consumption and noncommunicable diseases in India. Ann N Y Acad Sci 2014;1331:157-73

26. Earland J, Campbell J, Srivastava A. Dietary habits and health status of African-Caribbean adults. J Hum Nutr Diet 2010;23:264-71.

27. Ogna A, Forni Ogna V, Bochud M, et al. Prevalence of obesity and overweight and associated nutritional factors in a population-based Swiss sample: an opportunity to analyze the impact of three different European cultural roots. Eur J Nutr 2014;53:1281-90.

28. Jebb SA, Aveyard PN, Hawkes C. The evolution of policy and actions to tackle obesity in England. Obes Rev 2013;14(Suppl 2):42-59.

29. Misra A, Sharma R, Gulati S, et al, National Dietary Guidelines Consensus Group. Consensus dietary guidelines for healthy living and prevention of obesity, the metabolic syndrome, diabetes, and related disorders in Asian Indians. Diabetes Technol Ther 2011;13:683-94.

30. Aballay LR, Osella AR, De La Quintana AG, et al. Nutritional profile and obesity: results from a random-sample population-based study in Córdoba, Argentina. Eur J Nutr [Epub ahead of print 31 Mar 2015]. 